\title{
MULTIMÍDIA \\ NA EDUCAÇÃO
}

\section{Combinação de linguagens diferentes e atividades multidisciplinares favorecem a formação integral e humanista}

Antes de qualquer discussão sobre esses dois temas necessariamente correlatos Multimídia e Educação - cabe defini-los, do ponto de vista adotado neste artigo. Limitamos aqui o amplo assunto da informática à multimídia, que já é bastante abrangente.

Multimídia é uma linguagem eletrônica, produzida em computador, que une diferentes linguagens de arte e comunicação texto, imagem, som, animação, vídeo - e com a qual o usuário pode interagir. Uma multimídia pode ser apenas uma apresentação de alguns minutos. Ou uma enciclopédia inteira pode ser posta em forma de multimídia. O CD-Rom (pronuncia-se "rom", com a letra $o$ e não "rum", como pegou a moda no Brasil) é uma multimídia, mas nem toda multimídia precisa transformar-se em $C D$-Rom. O $C D$-Rom é uma embalagem em forma de disco laser de informações postas em linguagem multimídia.

Uma multimídia (de pequenas proporções) pode ser produzida por qualquer pes-

\section{A AUTORA \\ Dora Incontri \\ Jornalista, mestre em História e Filosofia da Edu- cação pela Faculdade de Educação da USP. Auto- ra de Estação Terra, comunicação no tempo e no espaço, editora Moderna.}

soa que domine relativamente os programas (softwares) específicos. Há muitos que podem ser usados por não profissionais, com bastante facilidade. Num programa de texto, pode-se, por exemplo, escrever uma história; num outro programa, grava-se uma trilha sonora; num outro, criam-se imagens de fundo ou uma animação e junta-se tudo num quarto programa, específico, para a produção final de multimídia. Há programas especiais para crianças.

O CD-Rom, por sua vez, é uma nova espécie de livro, que não contém apenas informações escritas, mas imagens e sons, que se complementam para transmitir um conhecimento ou uma forma nova de Arte.

A Educação não pode ser definida tecnicamente como multimídia e CD-Rom, pois sua concepção depende de certas premissas filosóficas a respeito do homem e do mundo. Aqui adotamos a perspectiva humanista e buscamos inspiração em autores que conseguiram abarcar o homem em suas múltiplas facetas, propondo teorias pedagógicas mais condizentes com sua natureza. Comenius (1592-1670), por exemplo, considerado o iniciador da Pedagogia moderna, afirmava que a finalidade da Educação é "formar o homem para a sua humanidade"I. 
Isso significa favorecer o desenvolvimento de todas as potencialidades humanas, dentro da singularidade de cada indivíduo. Mas esse desenvolvimento não é realizado de fora. Pestalozzi (1746-1827), educador suíço, discípulo de Rousseau, completa o raciocínio de Comenius, advertindo que "a criança não é uma tábula rasa, que pode ser descrita exteriormente como um recipiente vazio e que deve ser preenchido com matéria estranha, para se conseguir algo; mas sim como uma força real, viva e autônoma, que já no primeiro instante da sua existência age coordenando organicamente seu próprio desenvolvimento e expansão..."2.

\section{REVOLUÇÃO ORIENTADA}

Postas esşas definições e premissas, as questões a serem debatidas podem se resumir assim: a multimídia representa por si só uma revolução na Educação? Em que medida a nova tecnologia avança modificando padrões e em que medida podemos orientála? E que orientação lhe devemos imprimir?

Dizia McLuhan, nos anos 60: "Daqui a algumas décadas, será fácil descrever a revolução na percepção e motivação humanas que resultou da contemplação dessa tela mosaica da imagem de televisão. Hoje em dia, é completa futilidade querer debater o assunto"3. É difícil apreender os contornos de uma revolução, quando estamos nela mergulhados.

Mas também não é lógico achar que o impacto de uma nova tecnologia possa modificar-nos, sem que possamos segurar-lhe as rédeas. Lévy, um estudioso do tema, avisa: "Por que não aproveitar esse momento raro em que se anuncia uma cultura nova, para orientar deliberadamente a evolução em curso? (...) A técnica propõe, o cidadão dispõe"4.

O sujeito de uma revolução é sempre o homem. O progresso tecnológico pode nos atiçar, nos empurrar, mas não promove por si só um salto qualitativo na história.

E se falamos em revolução, reconheça-se em primeiro lugar que uma revolução é necessária na Educação, independente do fato "multimídia" ou "informática". Estes fatores tecnológicos podem instrumentalizar umas tantas mudanças, que seriam necessárias mesmo sem o seu advento. Mas este advento tornou-as de certa forma mais necessárias.

Voltando às nossas premissas iniciais, emprestadas de Comenius e Pestalozzi, digamos que a educação atual não atende a dois princípios básicos: ela não forma integralmente o homem, ao invés, fragmenta conhecimentos, que ficam sem relação entre si, e desenvolve potencialidades parciais, apelando mais à memória que ao raciocínio, mais à passividade que à iniciativa, negligenciando a criatividade, a estética e a ética.

\section{A REPRESENTAÇÃO DA ÁRVORE}

Para focalizar alguns aspectos dessa discussão, recorremos à imagem da árvore. Tanto Comenius quanto Pestalozzi fizeram dela largo uso. Vejamos sua aplicação ao nosso tema.

2. PESTALOZZI, Johann Heinrich. Gesammelte Werke in zehn Bänden. v.10. Zurique: Rascher, 1945.

3. McLUHAN, Marshall. A Galáxia de Gutenberg. São Paulo: Companhia Editora Nacional, 1977. p.363.

4. LÉVY, Pierre. Cyberespace et Démocratie. Pour l'intelligence collective. (Ciberespaço e democracia. Pela inteligência coletiva.) In: Le Monde Diplomatique. Paris: XLIl (499), 25, out. 1995. 
Educação para todos, abolição de castigos, escola humanista e ativa, aprendizagem global e estimulante, partindo do interesse e da observação - todas essas são idéias formuladas por Comenius. Autor de obras-primas da Pedagogia, como a Didactica Magna e a Pampaedia, foi o primeiro a lançar um livro didático e ilustrado para crianças, o Orbis sensualium pictus. Humanista e universalista, Comenius buscava uma sabedoria do todo - a Pansofia, a que todos tivessem acesso.

Renascentista e partidário da Reforma, não havia abdicado das raízes metafísicas em seu pensamento, e sua representação do mundo como árvore indicava a harmonia $\mathrm{e}$ a relação orgânica e inteligente entre todos os seres vivos e todos os elementos da natureza. Haveria uma conexão causal, inteligível e bela entre tudo o que existe, cujas raízes estariam no poder, na sabedoria e na bondade do Criador.

À parte o seu aspecto religioso, cabe assinalar o quanto essa visão unificada e harmônica do mundo se transferia para sua proposta pedagógica. $\mathrm{O}$ conhecer deste todo universal deveria ser pansófico, ou seja, deveria abranger os conteúdos filosóficos, científicos, estéticos, éticos e religiosos, de forma entrelaçada e jamais fragmentada.

Desenvolver o ser humano plenamente, de forma cativante e ativa, significava também que conteúdos de aprendizagem deveriam ter sempre um sentido para o sujeito.

Tanto Comenius quanto Pestalozzi se insurgiram contra o que ambos chamavam "papaguear" alguma coisa, aprendida por memória, sem significado real para o educando. A pansofia não era uma utopia, segundo a qual todos os homens deveriam ingerir to- do o conhecimento humano. Mas, primeiro, que todos tivessem o acesso assegurado a esse conhecimento e segundo, que cada um pudesse construir seu conhecimento de forma integrada e coerente, dentro de uma visão de mundo verdadeira e significativa.

As concepções de Pestalozzi revelam parentesco evidente com Comenius. Mas talvez seja seu o mérito principal de afirmar e analisar a base afetiva da Educação. Ele teorizou e demonstrou que é a partir do elo afetivo, criado entre educador e educando, que se desenvolve um processo pedagógico eficaz.

Em duas ocasiões Pestalozzi usou com maior desenvolvimento a imagem da árvore. Citaremos aqui apenas a mais pertinente ao nosso tema. Ele toma a árvore em seu sentido real, como objeto de conhecimento. Aliás, a sua insistência em colocar o sujeito em contato direto com o objeto de aprendizagem é ainda maior do que em Comenius. Mas em Pestalozzi há sempre uma intermediação humana no processo de aprendizagem. Convocando a mãe - como elo afetivo mais próximo - a ser a intermediária entre o mundo e a criança, Pestalozzi tira da observação de uma árvore o desenvolvimento e o exercício dos órgãos físicos, a capacidade de apreender o todo e as partes de um objeto (como da própria realidade), a introdução de todas as idéias de função, qualidade, sujeito, objeto, através da linguagem e do diálogo e, afinal, a inserção de tudo isso numa atmosfera de amor, que começa na relação mãe-filho, para se estender até um sentimento religioso.

"Mãe, segue ofio, que a natureza te indica; não entregues ao puro acaso, se $e$ quando uma árvore se apresentar aos olhos de teu filho e o que ele por si próprio observará nela; mostra-lhe a árvore, mostra-lhe as partes que nela identificas; (...) mostralhe ao lado da gigantesca forma do carvalho e da tília, também o pequeno germe que bro- 
ta de seu grão; mostra-lhe como esse germe se desdobra, como ele cresce, se torna uma arvorezinha e depois, uma árvore que vive várias vezes o periodo da vida humana; mostra-lhe (...) quando desabrocham as flores, como estas depois caem e delas germina o fruto, como este cresce aos poucos, tornando-se maduro e, finalmente, também cai; como depois de tudo isso a árvore se desfolha e se inclina para a sua paz de inverno; dize-lhe quando ele a tiver sob os olhos: $o$ todo - raiz, tronco, ramos, galhos se chamam juntos árvore; (...) dize-lhe que se ele a vê cheia de folhas, que a chame de frondosa, e se ela está sem folhas diante de seus olhos, então que a chame desfolhada. Mãe, (...) ensina-lhe a pronunciar a frase: "estar sob a sombra da árvore", exatamente no instante em que ele está sob essa proteção; ensinalhe a pronunciar que a pêra é gostosa, suculenta, farinhosa, doce, no momento em que ele a está comendo; põe-lhe na alma o pensamento de que os frutos das árvores refrescam o homem, no momento em que ele realmente estiver sendo refrescado por eles; (...) $e$ se teu filho se mostra cheio de gratidão $e$ amor por ti, porque lhe dás nas mãos o fruto doce da árvore, então enquanto ele estiver se refrescando com o prazer do fruto, eleva teu filho para aquele que, antes de a árvore ser árvore, disse-lhe 'sê' e dize a teu filho: 'Ele é meu Pai, ele é teu Pai'"'5.

\section{AS REFORMAS NECESSÁRIAS NA EDUCAÇÃO}

Justifica-se invocar a imagem da árvore, porque ela representa tanto a organicidade das coisas e do conhecimento quanto o objeto real de observação e apreensão. A multimídia pode muito bem ser asssimilada à concepção de árvore. O próprio Pierre Lévy é autor do livro Les arbres de connaissances (As árvores de conhecimentos) e a Escola do Futuro (da USP) adotou como logotipo o símbolo de uma árvore esquematizada.

Relacionando as inspirações dos autores citados, as necessidades da Educação atual e a contribuição e os limites da multimídia para melhorá-la, fixemos algumas conclusões. Para fazermos Educação de verdade e não apenas produção em massa de candidatos a vestibular, é preciso:

1) Buscar uma formação interdisciplinar, em que o conhecimento se entrelace. Um $C D$-Rom pode favorecer a representação orgânica, não linear e não fragmentada do conhecimento.

2) Devolver a iniciativa da aprendizagem ao educando. (Essa é uma das propostas básicas do Construtivismo, mas que, às vezes, focalizado por certos autores, tende a reduzir o ser humano ao seu aspecto apenas cognitivo ou, por outros, ao aspecto sócio-político. Por isso, recorremos a autores que faziam um Construtivismo avant la lettre, mas com uma concepção mais abrangente do homem). A consulta livre de CD-Rom, segundo o interesse e o ritmo de cada um, pode ajudar esse propósito. Também a produção de multimídias por parte do aluno pode desenvolver nele a auto-construção das linguagens envolvidas no processo.

3) É preciso trazer de volta a realidade concreta para a Educação. A representação nu-

5. PESTALOZZI, Johann Heinrich. Über den Sinn des Gehörs in Hinsicht auf Menschenbildung durch Ton und Sprache. (Sobre o sentido da audição em relação à formação humana pelo som e pela palavra) In: Kleine Schriften zur Volkserziehung und Menschenbildung. (Pequenos escritos para a educação popular e a formação humana) Bad Heilbrunn: Ed. Julius Klinkhardt, 1983. p.68/69. 
ma multimídia é sem dúvida muito mais complicada e realista do que a representação livresca. Ainda assim, o laboratório, a tinta, a natureza, a vivência têm urgência de figurarem no aprendizado. A árvore não pode ser apenas uma representação. É preciso apalpá-la e saborear seus frutos, como queria Pestalozzi.

4) Proporcionar o desenvolvimento global do indivíduo, isto é, ajudá-lo a desabrochar intelectual, moral, estética, psíquica e fisicamente. Aí se nota com mais clareza que um instrumento como o computador deve ser apenas um elemento de um processo pedagógico muito mais profundo, onde o papel preponderante cabe ao educador. Sua relação afetiva com o educando, seu equilíbrio psicológico, sua postura ética e existencial - tudo isso tem papel decisivo no crescimento harmonioso do indivíduo.

Resumo: $\mathrm{O} C D$-Rom é uma linguagem multimídia, de uso multidisciplinar, bastante útil para a Educação mas, ressalta a autora, os recursos eletrônicos devem ser incorporados sempre com o objetivo do exercício de uma pedagogia voltada para a formaçăo integral (não fragmentada) do aluno e preocupada com o desenvolvimento global do indivíduo.

Palavras-chave: $C D$-Rom, multimídia, educação, multidisciplinar, humanismo.
Se faltar essa base humana na Educação, nem todos os instrumentos pedagógicos e nem todas as realidades virtuais do mundo poderão resgatar o homem.

E ainda que reconheçamos o quanto um $C D$-Rom - produto acabado de multimídia - pode contribuir numa proposta de mudança educacional, é preciso verificar se o instrumento está sendo convenientemente usado. Se aproveita todas as suas possibilidades de conhecimento interativo e dinâmico; se respeita e estimula o espírito crítico e a criatividade do usuário; se busca elevados padrões de Ética e Estética. Enfim, é preciso evitar que mais este meio possível de Educação - como o livro, o cinema, a televisão e o rádio - se transforme em mais um reduto de lixo cultural e de exploração capitalista desenfreada.

Abstract: The CD-Rom is a multimidia language of multidisciplinary use very helpful for education but, as the author points out, the electronic resources must be incorporated aiming the practice of a pedagogy centered on the whole (not fragmented) development of the student and worried about the global evolution of the person.

Key-words: multimidia, education, multidisciplinary, humanist. 